\title{
Kutsal Metin ve Otorite: Tarihsel-Fenomenolojik Bir Analiz
}

\author{
Burhanettin TATAR.
}

The Sacred Text and Authority: A Historical-Phenomenological Analysis

Citation/(C: Tatar, Burhanettin, (2017). The Sacred Text and Authority: A Historical-Phenomenological Analysis, Milel ve Nihal, 14 (1), 64-76.

Abstract: The authority that has been accepted as a sacred phenomenon by many The problem of relationship between sacred texts and authority is generally explored within two seemingly opposite approaches: Genetic and historical. However, the essential problem, which can be grasped within these approaches, reveals itself when interpretive traditions or strategies of interpretation of sacred texts transform themselves into an authoritarian character which hides itself behind the politics of turning sacred texts to an image or mask under the label of 'sacred authority'.

Key Words: Sacred text, authority, authoritarian, modernity, tradition.

Atıf/C): Tatar, Burhanettin, (2017). Kutsal Metin ve Otorite: Tarihsel-Fenomenolojik Bir Analiz, Milel ve Nihal, 14 (1), 64-76.

Öz: Kutsal metinler ve otorite arasındaki ilişki sorunu, genel olarak, kökenci

Prof. Dr., Ondokuz Mayıs Üniversitesi, İlahiyat Fakültesi, İslam Felsefesi Anabilim Dalı [burhantatar@hotmail.com] 
ve tarihsel yaklaşımlar içinde birbirine ilk elde zıt görünen formlarda ele alınmaktadır. Ancak bu ilişki içinde asıl sorun, kutsal metinlerin otoritesini bir imge veya maskeye dönüştürerek kendisini gizleyen yorum geleneklerinin veya stratejilerinin otoriter karaktere bürünmesiyle ortaya çıkmaktadir.

Anahtar Kelimeler: Kutsal metin, otorite, otoriter, modernlik, gelenek.

Kutsal metinler, beşeri-dünya-için(de) otoriteye dönüşürken, kaç1nılmaz olarak birçok paradoksal durumun ortaya çıkmasına yol açarlar. Bu paradokslardan bazıları şunlardır: Kutsal metinler bir taraftan bu dünyayı aşan mutlak öteki bir varlığın (Tanrı) dünya içinde sözü, temsili, dilsel boyutta zuhuru (presence) gibi algılanırken $^{1}$, diğer taraftan onlar ancak kendilerine inanan topluluğun gözünde kutsaldırlar. Benzer şekilde onlar asla dil içinde varlığı açı̆̆a çıkamayacak sonsuz (metafiziksel) bir varlığa kendilerinin kaynağ (origin) olarak işaret ederlerken, diğer taraftan kutsal olabilmek için belli bir dil, imge ya da nesne içinde duyulur, görülür ya da dokunulur olmak durumundadırlar. Yine zamansız bir varlığın değişmez bir söylemi olarak mutlak hakikatin yegane temsili veya tezahürü olarak ele alınırlarken, diğer taraftan kutsallık statülerinin korunması ancak sürekli değişen tarihsel ortamlar içinde yenilenen ve farklılaşan yorumlara bağımlıdır. Bu paradoksal görünümleri, yukarıda belirttiğimiz üzere, kutsal metinlerin hem 'metafiziksel' (Illahi) hem de 'beşeri-dünya-için' ve ‘beşeri-dünya-içinde' kategorilerine aynı anda ait olmalarıyla yakından ilişkilidir.

Bu durum ister istemez 'kutsal metin' ve 'otorite' kavramlar1nın yan yana kullanılmasıyla oluşan 'kutsal metnin otoritesi' ifadesinde derin bir anlam belirsizliğine yol açabilmektedir. 'Ínananların gözünde kutsal olanın aynı zamanda otorite haline geleceği' düşüncesi ilk başta oldukça kolay kabul edilebilir bir fikir olarak görünmektedir. Ancak hem kutsal metnin hem de otoritenin asla boşlukta değil, aksine daima dönüşüm içinde bulunan tarihsel ortamlar

\footnotetext{
${ }^{1}$ Farklı dini geleneklerde kutsal metin algısı için bkz. Thomas Jansen, "Sacred Text", in The Wiley-Blackwell Companion to Chinese Religions, edit. R. L. Nadeau, John Wiley \& Sons, Ltd, Chichester, UK, ch. 13 http://onlinelibrary.wiley.com/doi/10.1002/9781444361995.ch13/references; http:/www.academia.edu/8078597/Sacred_Text (21.06.2017)
} 
içinde tezahür edebildiğine dikkat kesildiğimizde, her şeyden önce kendimizi form ve muhteva arasındaki ayrışmanın ortasında buluruz. Zira kutsal metinlerin kanonikleşmesi ile artık metinlerin formunda bir değişimin olmayacağı kabul edilirken, diğer taraftan tarihsel süreç içinde metinlerin hangi anlamda otorite olabileceği daima açık uçlu yani önceden kestirilemez bir muhteva ile ilgili bir durum olarak kalmaktadır. Bu hususun daha iyi fark edilebilmesi için, kutsal metinlerin otoritesinin tarihsel süreç içinde ne tür dönüşümlere maruz kaldığını izah sadedinde bazı teorik hususları ele almak yararlı görünmektedir.

Bu teorik hususların başında 'kutsal', 'metin', 'otorite' kelimeleri arasında ne tür bir genel semantik bağın bulunduğu sorunu gelmektedir. Daha açık deyişle, sırasıyla metafizik, dil, toplum alanlarına ait kutsal, metin ve otorite kelimeleri yan yana kullanıldığında, hangisi diğerlerinin anlaşılması için bir perspektif, kural veya hareket noktası haline gelmektedir? Bu üç kelime yan yana geldiğinde metafiziksel, dilsel ve toplumsal alanlar arasında kendiliğinden bir bağ kurulmuş olmakta mıdır? Yoksa birbirinden farklı bu alanlar arasındaki semantik ayrışma daha fazla mı derinleşmektedir? Bu üç ayrı alana işaret eden kelimelerin -şayet varsa- 'ortak anlamı' hangi zeminde ortaya çıkmaktadır?

N. T. Wright'ın günümüzde 'otorite' kelimesinin sabit, anlamı kendiliğinden belirlenebilir bir nokta olarak alınması ve kutsal metinlerin bu sabit noktaya göre kurgulanmasının ciddi sorun oluşturduğuna yönelik düşüncesi² dikkate alınmayı hak etmektedir. Wright'a göre, otorite kelimesinin siyasi, idari, ekonomik, hukuki vs. bağlamlarda kazandığı anlamlarından hareketle kutsal metnin otoritesi sorunu anlaşılamaz. Wright'nn burada sorun edindiği temel hususun anlaminı, muhtemelen M. Engelke'nin Zimbabve'de bir kiliseye mensup olup kendilerini Cuma Havarileri olarak adlandıran misyonerlere dair yaptığı hacimli çalışmasının başlı̆̆ında ( $A$ Problem of Presence: Beyond Scripture in an African Church) daha rahatça kavrayabiliriz. Kuşkusuz bu başlık, Afrika' da kutsal metinleri okumayı reddeden bir kilise mensuplarının Tanrı ile 'şimdi-burada'

\footnotetext{
${ }^{2}$ N. T. Wright, "How Can The Bible Be Authoritative?", Vox Evangelica, 1991, 21,

7-32 http://ntwrightpage.com/2016/07/12/how-can-the-bible-be-authoritative/ (21.06.2017)
} 
mistik ve metafiziksel olarak iletişime geçmeye çalışmalarına odaklanması anlamında radikal bir durumun ifadesi olarak görülebilir. Zira bu kilise mensuplarına göre, kutsal metinler, Tanrı ile insan arasındaki canlı iletişimi yani Tanrı'nın şimdi-burada tezahürünü (presence) engelleyen bir işlev görmektedirler. ${ }^{3}$

Ancak Cuma Havarilerinin bu yaklaşımı, daha geriye baktığ1mızda Yahudi, Hristiyan ve İslam tarihinde ortak bir sorunu fark etmemize yardım etmektedir. Bu sorun felsefi olarak 'huzur (mevcudiyet, presence) ve gaybubet (yokluk, absence)' olarak dile getirilmektedir. Bu kavramların karşımıza çıkardığı ana sorunlar şunlardır: Kutsal metinler ne anlamda kutsaldırlar? Tanrı (mutlak öteki, sonsuz) bu sınırlı dilsel yapılar içinde hangi boyutta açığa çıkabilmektedir? Dahası Tanrı ile iletişimde kutsal metinler yegâne araç mıdırlar? Yoksa onlar başka ilahi tezahürlerin fark edilmesi için bize işaret mi sunarlar?

Özellikle Hristiyanlıkta İsa'nın -zamansal ve mekansal düzlemde canlılık ve somutlaşma anlamında-- 'Tanrı'nın Sözü' olarak anılması ve İncillerin bu Söz'e dair bir tecrübenin anlatısı veya metafiziksel olarak onaylanmış bir tanığı olarak kabul edilmesi kutsal ve metin kavramları arasındaki tarihsel ve metafiziksel ayrışmayı işin başında getirmektedir. Bilahare Luther' in 'sola scriptura' anlayışı, Papanın kontrolündeki Katolik kilisesini devre dışı bırakarak kutsal ile metin arasındaki bağı metafiziksel olarak güçlendirmeyi amaçlasa da (genel deyimle, 'insan papa'nın yerine 'kağıt papa'yı koysa da) sorun çözülmüş görünmemektedir. Zira ne olursa olsun Kutsal (Tanrı) ile metin (scripture) iki ayrı şey olarak karşımıza çımaktadır. Dolayısıyla hep aynı soru ile yüzleşmek kaçınılmaz hale gelmektedir: Kutsal olarak kabul edilen metinler, Tanrı ile insan arasındaki canlı iletişimin bittiğini (gaybubet) yani Tanrı'nın mutlak anlamda Öteki olarak kaldığını mı temsil ederler? Yoksa her çağda insan ile Tanrı arasındaki bağın yeniden kurulmasına imkan veren huzur (mevcudiyet)'u mu mümkün kılarlar?

Fark edileceği üzere, bu sorulara verilecek cevaplara göre, otorite kelimesi farklı anlam ve statü kazanacaktır. Zira gaybubet (absence) esas alındığında, artık metnin kendisi Mutlak Öteki olan

\footnotetext{
${ }^{3}$ Ayrıntılı bilgi için bkz. Matthew Engelke, A Problem of Presence: Beyond Scripture in an African Church, University of California Press, Berkeley, 2007.
} 
Ezeli Şahsiyeti şimdi-burada temsil eden gayri şahsi bir tarihsel otorite haline gelecektir. Dolayısıyla o, sorunların çözümü için sürekli kendisine başvurulan bir anlam kaynağına dönüşecektir. Huzur (presence) ya da mevcudiyeti esas alan yaklaşımlarda ise metnin kendisi değil, sadece Tanrı otoritedir. Buna bağımlı olarak, metin yalnızca Tanrı'nın otoritesinin tarihsel ortam içindeki bir imgesi ya da sembolüdür. Kısacası o bu durumda gerçekliğin kendisi ile karıştırılmaması gereken bir resimden ibarettir. ${ }^{4}$ Onun otoritesi ancak sembolik (dolaylı, ikincil) bir otorite olarak kalabilir.

Bu iki yaklaşım, felsefi olarak daha derinliğine ele alındığında, karşımıza ikili karşıtlık (binary opposition) durumunu hatırlatan yeni bir boyutu çıkarmaktadır: Kutsalın bir başka ifadesi olan mutlak ötekilik yani 'yabancllık' ile metnin beşeri dilde ortaya çıkmasından kaynaklanan 'aşinalık' durumu. Tanrı, varlık tarzı açısından, insanın doğrudan göremeyeceği, bilemeyeceği, kavrayamayacağı, dolayısıyla yabancı kalacağı bir varlık iken, onun sözü veya sözünün temsili olarak metin bize dilimiz kadar aşina olan bir şeydir. Bu yabancilık ve aşinalık durumunun, mevcudiyet ve gaybubet sorunu bağlamında, kutsal metinlerin otoritesinin ne anlama geleceğinin belirlenmesiyle ilgili bir nokta olduğunu belirtmeliyiz. Gaybubet esas alındığında metnin otoritesi aynı zamanda otonomi anlamına gelmektedir. Yunanca auto ve nomos kelimelerinden türetilen otonomi, kendi kuralını kendisi koyan ve ona göre iş gören anlamına gelmektedir. Kısacası otonomi, kendi dışında bir kaynağa ihtiyaç duymayan ve başkasının kuralına boyun eğmeyen anlamında yabancilık durumuna atıf yapmaktadır.

Bu bağlamda özellikle İslam düşüncesinde İbn Hazm'ın zahiriliğinin temel vurgusunun tam da bu şekilde bir otonomi (yabancllık) olduğu kolayca fark edilebilir. İbn Hazm, Kur'an'ın anlamının belirlenmesi için diğer kutsal metinlere veya Cahiliye dönemine ait şiirlerine bakılmasına karşı çıkar. Ona göre, Kur'an, kendisine Hz.

\footnotetext{
${ }^{4}$ Gerçeklik ve resim (imge) ilişkisi, özellikle modern dönemde hem sanat hem de felsefi düşünce açısından ciddi bir ilgi ve tartışma konusudur. Resmin gerçeklik ya da "şey" in yerini tutup tutamayacağ 1 ve tutarsa ne ölçüde tutabileceği konusu özellikle Rene Magritte"nin meşhur "Ceci n'est pas une pipe" (Bu bir pipo değildir) tablosu ve bu tablo üzerine Foucault"nun yazdığ "Bu Bir Pipo Değildir" adlı yazısında tartışma konusu edilmiştir. Bkz. Michel Foucault, Bu bir Pipo Değildir, Çev. Selahattin Hilav, YKY: İstanbul, 2016.
} 
Peygamber döneminde gördüğü iş bağlamında (yani belli bir tarihsel uzaklık ya da mesafeden) bakılarak kavranabilecek bir metindir. Bunun anlamı şudur: Kur'an'ın otoritesi, kıyas vb. rasyonel yorumlarımızla müdahale edemeyeceğimiz, dolayısıyla onun 'biz ve o' arasındaki belli bir yabancılaşma mesafesini koruyan otonomisinden kaynaklanır. Zahirilik öncesi Hariciliğin de benzer şekilde Kur'an'a mutlak bir otonomluk atfettiğini yeri gelmişken ilave etmeliyiz.

Geldiğimiz noktada otorite ile otonomi arasındaki bağın daha açık hale getirilmesi gerekmektedir. Latince kökenli otorite (auctorite) kelimesi, temelde auctor (yazar, yaratıc1) kelimesine dayanmakta ve görüşleri doğru ve geçerli kabul edilen yazar imgesini ön plana çıkarmaktadır. Ortaçă̆ ve sonrasında ise otorite kelimesinde ağırlığın yazardan yazarın söylediği şeye kaymasıyla metin imgesi ön plana çıkmış görünmektedir. Bu yüzden akıl ve otorite kelimeleri, özellikle Aydınlanma dönemi ile birlikte (I. Kant felsefesinde açıç̧a fark edileceği üzere) karşıtlık arz etmeye başlamıştır. Bu tarihsel dönüşüm, daha önce bahsettiğimiz gaybubet ve huzur merkezli yaklaşımlarda 'kutsal metnin otoritesi' ele alınırken ağırlık noktalarının nasıl farklılaştığını daha rahat fark etmemize katkı sağlamaktadır. Gaybubet merkezli yaklaşımda metin ağırlık kazanırken, huzur merkezli yaklaşımda auctor (yazar, şahıs olarak Tanrı) ön plana çıkmaktadır.

Şu ana değin büyük oranda köken veya başlangıç durumunu ön plana çıkararak kutsal metinlerin otoritesi sorununu analiz ettiğimizi belirtmemiz gerekir. Bunun nedeni, kutsal metinlere sahip dini geleneklerin, özellikle modern dünyada, çoğu kez kökencilik açısından konuya yaklaşmaları ve kendilerini modern bilim ve felsefeler karşısında meşrulaştırma çabalarıdır. Zira bu dini geleneklere göre, kutsal metin gaybubet merkezli ele alındığında, onu orijinal haliyle tecrübe edenler daha sonraki nesiller için bir model (paradigma)

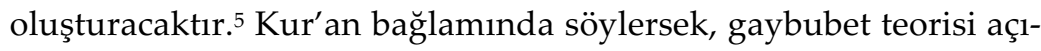
sindan, Kur'an'ın inzaline ilk tanıklık eden Hz. Peygamber ve onun yanında bu tecrübeyi yaşayanlar (ashab), sadece metne değil aynı

\footnotetext{
${ }^{5}$ Her ne kadar oldukça modern oluşumlar olsa da, 'fundamentalist' (köktenci) şeklinde nitelenen muhtelif dini hareketlerin gaybubet merkezli bir kökencilik tasavvuruna sahip oldukları söylenebilir.
} 
zamanda metnin ortaya çıkışı esnasında kutsalın tecrübesine de tanık oldukları için birer model haline gelirler. Hristiyanlık açısından ise bu durum, havarilerin Hz. İsa ile ilgili tecrübelerinin Hristiyanlar için birer model haline gelmesi demektir.

İslam düşüncesinde Şia (on iki imam tasavvuru) ve kısmen tasavvufta, Hristiyanlıkta ise Katolik mezhebinde görülebileceği üzere, huzur eksenli yaklaşımda kökencilik, tarihin belli bir safhasında olup biten durumu değil, devam etmekte olan bir süreci gösterir. Dolayısıyla kutsal kitabın temel işlevi, yaşamakta olan insanlarla Allah arasında şimdi-burada canlı bir bağ kurma (huzur) vesilesidir. Elbette iki farklı köken tasavvuru paralel şekilde kutsal metnin yorumlanma tarzını da etkilemektedir. Zira artık tekrarlanamaz bir tarihsel safha anlamında kökenci yaklaşımlarda (sözgelimi, tarihselci, modernist Kur'an anlayışlarında) metnin $\mathrm{Hz}$. Peygamber dönemindeki (dilsel) anlamina sadakat yorumun en önemli kuralına dönüşebilmektedir. Buna karşılık süreç olarak kökencilik'te alegorik, sembolik veya işari yorumlar ön plana çıkmaktadır.

İlk başta kökenci yaklaşımın tam tersi görünen tarihsel yaklaşım (ki, tarihselci yaklaşım ile karıştırılmamalıdır) bize kutsal metnin otoritesinin ilk elde dikkat çekmeyen bir başka boyutunu fark ettirmektedir: Kutsal metinlerin otoritesi, her zaman bir gelenek yani tarihsel zaman sorunudur. Bir başka deyişle, kutsal metinler kendi geleneklerini oluşturamadıkları sürece otorite olamazlar. Buna göre, kutsallık iddiasında olan her metin, kutsal olarak yorumlanabilmek için, tarihsel zamana muhtaçtır. Zaman içinde söz konusu metinler, kendi yorum geleneklerini oluşturmaya yani tarihsel süreci etkileyerek şekillendirmeye başladıklarında kendi inananları açısından kutsal metin haline dönüşür ve kanonik hale gelirler.

Eliade'ın ab origine ve ab initio kelimeleriyle işaret ettiği kutsalın başlangıcı belirlemesi durumu, gerçekte, bir gelenek konusudur ve ancak araya belli bir tarihsel mesafe girdikten sonra (uzaktan) fark edilebilecek bir husustur. Almanca Ur-text kavramı da, kendi yorum geleneğini inşa eden asıl (kaynak) metin anlamında, kutsal metinlerin tarihsel yorumlar aracılığıla otorite haline gelmesine atıf yapar. Tarihsel yaklaşımın bize öğrettiği en önemli husus, ab origine ve Ur-text durumundaki radikal dönüşümlerdir. Sözgelimi Kur'an ve daha önce Hz. İsa'nın söz ve eylemleri, sözlü kültürde --doğru- 
dan iletişim formatı içinde-- bir kutsal metnin dünya ile iç içe girmesi anlamında otoriteye sahiptirler. Daha açıkçası, sözlü kültür içinde kutsal metinlerin, başlangıçta, sabitlenmiş ve kendisini tekrarlayan bir otoritesi yoktur. Aksine zamanın akışı içinde kutsal metinlerin yeni durumlara göre yeni şeyler söyleyebilen, dolayısıyla açık uçlu bir otoritesi söz konusudur.

Oysa sözlü gelenek yerini yavaş yavaş yazılı geleneğe bıraktığında ve kutsal metinler Mushaf veya Bible (ki temelde yazılı kitap veya parşömen tomarı anlamına gelmektedir) formunu aldığında sabit ve kendi içinde değişmez (kapalı) otoriteye dönüşürler. Bu yüzden kutsal metinler, kendi (yazılı) geleneklerinin oluşmasıyla sonsuza değin aynı şeyleri söyleyecek ve böylece tarihin değişiminden kendisini koruyabilecek tarih üstü metinler olarak algılanır. Böylece sonraki nesiller için, 'kutsal metnin otoritesi' tabirinde yer alan 'otorite' kelimesi, öncelikli bir perspektif ve tarihsel tecrübe haline gelmeye başlar. Zira sonraki nesiller ilk önce kutsal metnin etrafında temerküz eden binlerce yorum, eser, eylem, adet, efsane, anlatı, giyim kuşam, yemek, mimari yapılar, aile, toplum, dil vs. ile daha çok küçükken yüzleşmeye başlar ve kutsal metnin otoritesini hem inşa eden hem de ona ait olan alt-metin türlerini tecrübe ederler. Bilahare metnin kendisine ve en sonunda --şayet inaniyorsakutsalın kendisine doğrudan yönelme imkânını araştırır. Kısaca özetlersek, sözlü kültür içinde başlangıçta 'kutsal-metin-otorite' s1ralaması söz konusu iken, yazılı kültürde bilahare 'otorite-metinkutsal' sıralaması ortaya çıkmaktadır. Sözlü dini kültürde kutsal metnin otoritesi, büyük oranda açık uçlu ve değişim halinde iken, yazılı dini kültürde kapalı ve değişmez bir statü kazanmaktadır. ${ }^{6}$

Batı'da özellikle Aydınlanma döneminden ve İslam dünyasında 19. yüzyıl ortalarından itibaren ciddi boyut kazanan akıl (bilim)-iman (kutsal metin) arasındaki otorite sorunu, daha ziyade, kutsal metinlerin kendi geleneklerini oluşturarak statik bir otorite haline gelmeleriyle ilgilidir. Zira bir gelenek olarak kutsal metnin

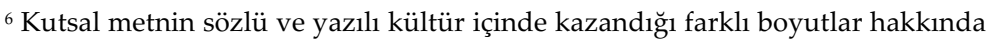
ayrıca bkz. Angelika Neuwirth, "Two Faces of the Qur'ān: Qur'ān and Mușhaf," Oral Tradition, 25/1 (2010): 141-156 http://journal.oraltradition.org/files/articles/25i/10_25.1.pdf (26.01.2017); Katharina Völker, "Mohammad Arkoun: The Qur'an Rethought" Journal of Religious Culture, edit. Edmund Weber, No: 189 (2014) http://web.uni-frankfurt.de/irenik/relkultur189.pdf (26.06.2017).
} 
otoritesi, sadece kutsalın tecrübesi veya kutsal ile bağ kurma sorununu değil, belki daha yaygın olarak bilgiyi, sosyal, hukuki ve siyasi alanı kontrol etmeye başlayan merkezi bir güç oluşumu sorunudur. Daha açık deyişle, kutsal metin, yol açtığı gelenek içinde yorumları, eylemleri, örf ve adetleri, aile yapısını, siyasi mekanizmaları vs. bir şekilde etkileyen ve gelenek içinde her şeyi kendi etrafında derleyip toparlayan bir çekim gücü haline gelmektedir.

$\mathrm{Ne}$ var ki, tarihsel süreç içinde, kutsal metinlerin, sembolik veya ontolojik anlamda çekim merkezi olmaktan çıkarılıp, başkaları üzerinde bir baskı mekanizmasını meşrulaştırma aracına dönüştürüldügü de iyi bilinen bir husustur. Görebildiğimiz kadarıla bunun temel nedeni, kutsal metinlerin otoritesini kabullenen ve elinde belli bir iktidarı bulunduran kişi ya da kurumların kendilerini başkaları üzerinde otorite olarak görmeye başlamalarıdır. Ancak bu noktada, aynı kökenden gelmelerine karşın, anlam açısından birbirine zıt şu iki kavram çoğu kez birbirinin yerini tutmaya başlamaktadır: otorite (authority) ve otoriter (authoritarian). ${ }^{7}$

Otorite kelimesi, en temelde, bilgi, feraset ve tatbikat açısından kişinin kendisinden daha iyi olanın görüşüne ve eylemine itibar etmesi yani o görüş, feraset ve tatbikatın doğru olduğunu düşünerek (özgürce) karar vermesine atıf yapmaktadır. Böylece, otorite, otoritesini başkalarının yorumlama ve algılama tarzlarına bağlı olarak ifşa edebilmektedir. Kısacası, otoritenin anlamı, kendisine yönelen insanların aklını kullanabilme ve otoriteyi tartışabilme gücüne referansla açığa çıkabilmektedir. Buna karşılık otoriter kavramı ise, kendi yaklaşımını, başkalarının olduğu gibi benimsemesini isteyen veya güç mekanizmalarını kullanarak bunu buyuran kişi ya da kurumu nitelemektedir. Dolayısıyla otoritede, başkaları üzerinde herhangi bir kontrol mekanizması yokken, bunun aksine otoriter, sadece buyurmakla yetinmeyip, ayrıca başkalarının tatbikatını

\footnotetext{
${ }^{7}$ Görebildiğimiz kadarıyla bu kavramsal karışıklık durumunu en iyi yansıtan örneklerden biri Gadamer ve Habermas arasında akıl versus otorite bağlamındaki tartışmalardır. Bu tartışmaların bir analizi için bkz. Kim, Donghyun, Reason,Tradition, and Authority: A comparative Study of Habermas and Gadamer, http://theses.gla.ac.uk/2812/1/2011KIMphd.pdf (26.06.2017); David Ingram, “The Historical Genesis of the Gadamer/Habermas_Controversy" https://kuscholarworks.ku.edu/bitstream/handle/1808/9065/Auslegung.v10.n01\&02.086151.pdf;sequence $=1$ (26.06.2017).
} 
kontrol etmekte olandır. Kısacası, otorite kutsal metinlerle ilgili bir kavram iken, otoriter, kutsal metinlerin yol açtığı geleneklerle ilgilidir. ${ }^{8}$ Ne var ki çoğu kez otoriter kişi ya da kurum, kendi icraatını kutsal metin aracılığıyla meşrulaştırırken, aynı zamanda kutsal metni dikkatlerin kendisine odaklandığı bir imgeye (daha açık söylersek, maskeye) dönüştürür.

İmge veya maske sorunu, çoğu kez, otorite ve otoriter kavramlarının birbirinin yerine kullanılmasına yol açan bir strateji konusudur. Asma Barlas'ın otoriterlik sorununa değinirken, otoriter olanın duruma göre dikkatleri metin, gelenek ve akıl üzerinde toparlad1ğına ilişkin tespitini ${ }^{9}$ bir tarafa kaydetmek uygun olacaktır. Bu noktada İslam tarihindeki en meşhur örnek, Muaviye ordusunun $\mathrm{Hz}$. Ali ordusu karşısında mızraklarına Kur' an sayfalarını takmalarıdır. Açıkçası bu durum, Muaviye ordusunda tecessüm eden otoriterlik sorununu hem ifşa eden hem de gizlemeye çalışan bir imge ya da maske üretme çabasıdır. Hakeza, bazı Emevi yöneticilerin ölümle cezalandırdığı kişiler için ‘Bu Tanrı'nın kaderiydi' şeklinde bir imge üretmeleri, otoriterliğin beraberinde bir maske üretimini de getirdiğinin ilgi çekici örnekleri arasındadır. Otoriterliğin Batı tarihinde en bilindik örneklerinden biri Ortaçă̆'da kilisenin ve modern dönemde Nazi yönetimlerinin üniversitelerin müfredatına ve içeriğine karışmaları, belirledikleri sınırı aşan hocaları cezalandırma yoluna gitmeleridir. Galile'nin engizisyonla tehdit edilmesi, başlı başına, kutsal metnin bir maskeye dönüştürülmesi olayıdır. Burada maskelenen, her şeyden önce otoriterin kutsal metin yorumunun kutsal metin gibi iş görmeye başlaması yani yorumun metin maskesi altında gizlenmesidir.

\footnotetext{
${ }^{8} \mathrm{~Hz}$. Ömer"e atfedilen şu söz, kanaatimizce, bu iki kavram arasındaki farkı yeniden görmemize katkı yapabilir: "Allah, Kur'an"dan ziyade, yöneticiler eliyle işleri idare etmektedir; çünkü insanlar öte dünyadan ziyade bu dünyada cezaya çarptırılmaktan daha fazla korkmaktadırlar." Bkz. Fauzi M. Nejjar, "Islam and Modern Democracy" The Review of Politics, Vol. 20, No. 2 (Apr., 1958), ss. 164180, https://edocs.uis.edu/Departments/LIS/Course_Pages/LIS411/readings/ Najjar_Islam_and_Modern_Democracy.pdf (26.06.2017).

9 Asma Barlas'ın kendi çalışmasında otorite (authority) kavramını kullandığını belirtmeliyiz. Ancak görebildiğimiz kadarıyla onun tartıştığı husus, otoriterlik sorunudur. Asma Barlas, "Text, Tradition, and Reason: Qur" anic Hermeneutics and Sexual Politics" Cardozo Law School, Yeshiva University, October 10-12, 2004, http://rojavaplan.com/uploads/library/gender/hermeneutics_recovery.pdf (26.06.2017).
} 
Kutsal metinler, otorite olmaktan çıııp, kişisel veya kurumsal bağlamda otoriter icraları meşrulaştırma aygıtına dönüştürüldügünde sosyal, siyasi, hukuki, bilimsel, ahlaki, sanatsal ve hatta dini alanda çok sayıda gerilimleri de beraberinde getirmiştir. İslam dünyasında klasik akıl-iman ilişkisi kadar modern dönemde bilim ve kutsal metnin otoritesi arasındaki ilişkiye odaklanılması bir tesadüf değildir. Zira her iki tartışmanın arka planında da daha ziyade kutsal metnin yol açtığı geleneğin (özellikle fıkhi /siyasi düşünce/tatbikat bağlamında) otoriter bir karaktere bürünmesi bulunmaktadır. Modern dönemde, modernist Müslüman yazarların kutsal metin ile gelenek arasını ayırmaya başlaması ve kutsal metnin ilk ortamına geri dönme parolasını oluşturması, bir ölçüde söz konusu yazarların günümüz İslam toplumlarında geleneğin iktidarlar elinde ve/veya toplum bilincinde otoriter uygulamalar için bir zemin sağlayabileceği kaygılarıyla ilgili görünmektedir.

Yazımıza son dönemde gelişmekte olan İslamofobia ve kutsal metnin otoritesi arasında kurulan ilişkiye kısaca değinerek son vermek yararlı olacaktır. Fark edileceği üzere, bu ilişki kutsal metin ve şiddet arasındaki evrensel ilişkinin güncel versiyonlarından biridir. İslamofobia'nın ilk elde dikkat çektiği husus, Kur'an'ın modern dönemde çok sayıdaki şiddet ve terör grubunun oluşumunda asıl saik olduğudur. 'İslami' diye etiketlenen birçok şiddet ve terör grubunun eylemlerinin İslamofobia'nın gelişiminde rol oynadığ 1 aşikârdır. Ancak dikkatle bakıldığında fark edileceği üzere, her hangi bir şiddet eylemine zemin olarak kullanılan her kutsal metin, aynı zamanda söz konusu şiddete maruz kalmaktadır. Bu açıdan şunu söylemek bizim için mümkün görünmektedir: Her ne kadar İslamofobia, ilk elde 'İslami' etiketi altında cereyan eden şiddet eylemlerine dikkat çekse de, daha geride o (İslamofobia), bizzat kutsal metne (Kur'an) uygulanmaya çalışılan küresel şiddeti meşrulaştırma politikası yani bir maske üretimidir.

Ne yazık ki, 'İslami' etiketi altında gerçekleştirilen her şiddet eylemi --aynı zamanda Kur'an'a uygulanan şiddet olduğu için-- İslamofobia formatı içinde işlevsellik kazanan küresel şiddetin yolunu açan bir öncü eyleme dönüşmektedir. Böylesi bir olumsuz durumun oluşmasında, Müslümanların uzun gelenekleri içinde Kur'an'ın anlaşılması için geliştirdikleri yorumlama tarzlarının za- 
man zaman otoriter bir karaktere bürünmesinin (yani Kur'an'a uygulanan bir şiddet politikasına dönüşmesinin) de büyük rol oynadığını belirtmek gerekmektedir. Kanaatimizce, kutsal metinleri anlamak için geliştirilen yorum tarzları aynı zamanda kutsal metne yönelik bir şiddet politikasına dönüştüğünde ortaya çıkan paradoksu makul bir şekilde çözmek, ${ }^{10}$ inanan insanların ahlaki ve dini sorumluluğudur.

\section{Kaynakça}

Barlas, Asma. "Text, Tradition, and Reason: Qur'anic Hermeneutics and Sexual Politics" Cardozo Law School, Yeshiva University, October 10-12, 2004. http://rojavaplan.com/uploads/library/gender/hermeneutics_recovery.pdf (26.06.2017).

Engelke, Matthew. A Problem of Presence: Beyond Scripture in an African Church, University of California Press, Berkeley, 2007.

Foucault, Michel. Bu bir Pipo Değildir, Çev. Selahattin Hilav, YKY: İstanbul, 2016.

Ingram, David. "The Historical Genesis of the Gadamer/Habermas Controversy" https://kuscholarworks.ku.edu/bitstream/handle/1808/9065/Auslegung.v10.n01\&02.086151.pdf;sequence $=1$ (26.06.2017)

Jansen, Thomas. "Sacred Text", in The Wiley-Blackwell Companion to Chinese Religions, edit. R. L. Nadeau, John Wiley \& Sons, Ltd, Chichester, UK, Ch. $13 . \quad$ http://onlinelibrary.wiley.com/doi/10.1002/9781444361995.ch13/references; http://www.academia.edu/8078597/Sacred_Text (21.06.2017)

Kim, Donghyun, Reason, Tradition, and Authority: A Comparative Study of Habermas and Gadamer, http://theses.gla.ac.uk/2812/1/2011KIMphd.pdf (26.06.2017).

Nejjar, Fauzi M. "Islam and Modern Democracy" The Review of Politics, Vol. 20, No. 2 (Apr., 1958), ss. 164-180 https://edocs.uis.edu/Departments/LIS/Course_Pages/LIS411/readings/Najjar_Islam_and_Mode rn_Democracy.pdf (26.06.2017).

${ }^{10}$ Bu hususta teklif ettiğimiz bir küçük öneri için bkz. Burhanettin Tatar, "Formasyon-Deformasyon-Transformasyon Diyalektiği Olarak Şiddet Bağlamında Din Dili", Din ve Şiddet: Tarihi, Dini, Siyasi, Kültürel, Sosyo-Psikolojik Boyutlarılala, ed. Faruk Sancar, Recep Tayyip Erdoğan Üniversitesi Yayınları, Ankara: 2016, ss. 371-378. 
Neuwirth, Angelik. "Two Faces of the Qur'ān: Qur'ān and Mușhaf", Oral Tradition, 25/1 (2010): 141-156 http://journal.oraltradition.org/files/articles/25i/10_25.1.pdf (26.01.2017).

Tatar, Burhanettin. "Formasyon-Deformasyon-Transformasyon Diyalektiği Olarak Şiddet Bağlamında Din Dili", Din ve Şiddet: Tarihi, Dini, Siyasi, Kültürel, Sosyo-Psikolojik Boyutlarıyla, ed. Faruk Sancar, Recep Tayyip Erdoğan Üniversitesi Yayınları, Ankara: 2016, ss. 371-378.

Völker, Katharina. "Mohammad Arkoun: The Qur'an Rethought" Journal of Religious Culture, edit. Edmund Weber, No: 189 (2014) http://web.uni-frankfurt.de/irenik/relkultur189.pdf (26.06.2017).

Wright, N.T. "How Can The Bible Be Authoritative?", Vox Evangelica, 1991, 21, 7-32. http://ntwrightpage.com/2016/07/12/how-can-the-bible-beauthoritative/ (21.06.2017). 